\title{
Psychostimulant-Induced Attenuation of Hyperactivity and Prepulse Inhibition Deficits in Adcyap1-Deficient Mice
}

\author{
Kazuhiro Tanaka, ${ }^{1 \star}$ Norihito Shintani, ${ }^{1 \star}$ Hitoshi Hashimoto, ${ }^{1}$ Naofumi Kawagishi, ${ }^{1}$ Yukio Ago, ${ }^{1,2}$ Toshio Matsuda, ${ }^{2}$ \\ Ryota Hashimoto, ${ }^{3}$ Hiroshi Kunugi, ${ }^{3}$ Akiko Yamamoto, ${ }^{1}$ Chihiro Kawaguchi, ${ }^{1}$ Takeshi Shimada, ${ }^{1}$ and Akemichi Baba ${ }^{1}$ \\ Laboratories of ${ }^{1}$ Molecular Neuropharmacology and ${ }^{2}$ Medicinal Pharmacology, Graduate School of Pharmaceutical Sciences, Osaka University, Suita, Osaka \\ 565-0871, Japan, and ${ }^{3}$ Department of Mental Disorder Research, National Institute of Neuroscience, National Center of Neurology and Psychiatry, Tokyo \\ 187-8502, Japan
}

Psychostimulants, including amphetamine, act as antihyperkinetic agents in humans with hyperkinetic disorder such as attention-deficit hyperactivity disorder and are known to be effective in enhancing attention-related processes; however, the underlying mechanisms have not been adequately addressed. Mice lacking the Adcyap1 gene encoding the neuropeptide pituitary adenylate cyclase-activating polypeptide $\left(\right.$ Adcyap $\left.1^{-1-}\right)$ display psychomotor abnormalities, including increased novelty-seeking behavior and hyperactivity. In this study, Adcyap $1^{-1-}$ mice showed sensory-motor gating deficits, measured as deficits in prepulse inhibition (PPI), and showed normal PPI in response to amphetamine. Amphetamine also significantly decreased hyperlocomotion in Adcyap $1^{-1-}$ mice, and this paradoxical antihyperkinetic effect depended on serotonin $1 \mathrm{~A}\left(5-\mathrm{HT}_{1 \mathrm{~A}}\right)$ receptor signaling. c-Fos-positive neurons were increased in the prefrontal cortex in amphetamine-treated Adcyap $1^{-1-}$ mice, suggesting increased inhibitory control by prefrontal neurons. Additionally, amphetamine produced an antihyperkinetic effect in wild-type mice that received the 5- $\mathrm{HT}_{1 \mathrm{~A}}$ agonist 8-hydroxy-2-(di-n-propylamino)tetralin. These results indicate that Adcyap1 ${ }^{-1-}$ mice act as a model of hyperlocomotion and PPI deficits and suggest that $5-\mathrm{HT}_{1 \mathrm{~A}}-\mathrm{mediated}^{-}$ pathways are important determinants of the psychostimulant-elicited, rate-dependent effects that are in a negative function of the baseline rate of activity.

Key words: neuropeptide; knock-out mice; psychostimulant; hyperactivity; prepulse inhibition; serotonin $5-\mathrm{HT}_{1 \mathrm{~A}}$ receptor

\section{Introduction}

Pituitary adenylate cyclase-activating polypeptide (PACAP) is a neuropeptide originally isolated from ovine hypothalamus based on its ability to stimulate adenylate cyclase in rat anterior pituitary cell cultures and a member of the vasoactive intestinal peptide (VIP)/secretin/glucagon family. It exerts multiple activities as a neurotransmitter or neuromodulator via three G-proteinlinked receptors, one PACAP-specific $\left(\mathrm{PAC}_{1}\right)$ receptor and two receptors that are shared with VIP $\left(\mathrm{VPAC}_{1}\right.$ and $\left.\mathrm{VPAC}_{2}\right)$ (Arimura, 1998; Vaudry et al., 2000; Hashimoto et al., 2006). Our recently developed mice lacking the Adcyap1 gene encoding the neuropeptide PACAP $\left(\right.$ Adcyap $\left.^{-/-}\right)$have marked phenotypes, including behavioral abnormalities (Hashimoto et al., 2001; Shintani et al., 2002; Kawaguchi et al., 2003; Tanaka et al., 2004). Adcyap $1^{-1-}$ mice are born in the expected Mendelian ratios but show a high early mortality rate before weaning. The surviving

\footnotetext{
Received 0ct. 13, 2005; revised March 24, 2006; accepted March 24, 2006.

This work was supported in part by Grants-in-Aid for Scientific Research and for Young Scientists from Japan Society for the Promotion of Science and by grants from Sankyo Foundation of Life Science and Taisho Pharmaceutical Company.

*K.T. and N.S. contributed equally to this work.

Correspondence should be addressed to either of the following: Dr. Hitoshi Hashimoto, Laboratory of Molecular Neuropharmacology, Graduate School of Pharmaceutical Sciences, Osaka University, 1-6 Yamadaoka, Suita, Osaka 565-0871, Japan, E-mail: hasimoto@phs.osaka-u.ac.jp; or Dr. Akemichi Baba, Laboratory of Molecular Neuropharmacology, Graduate School of Pharmaceutical Sciences, Osaka University, 1-6 Yamadaoka, Suita, Osaka 565-0871, Japan, E-mail: baba@phs.osaka-u.ac.jp.

DOI:10.1523/JNEUROSCI.4376-05.2006

Copyright $\odot 2006$ Society for Neuroscience $\quad 0270-6474 / 06 / 265091-07 \$ 15.00 / 0$
}

Adcyap $1^{-1-}$ females exhibit reduced fertility, which is partly attributable to reduced mating frequency, and inadequate maternal behavior. Furthermore, Adcyap1 ${ }^{-1-}$ mice display remarkable behavioral changes, including hyperlocomotion and jumping behavior in an open field, and increased novelty-seeking behavior. These salient phenotypes may be attributable to, at least in part, perturbed monoamine neurotransmission, because serotonin (5-HT) metabolism is slightly decreased in the cerebral cortex and striatum of Adcyap $1^{-1-}$ mice, and hyperactive behavior is ameliorated by the antipsychotic drug haloperidol (Hashimoto et al., 2001). However, the mechanisms involved and the pathophysiological significance still remain unclear.

It is commonly accepted that changes in dopaminergic tone highly correlate with alterations in locomotor activity. Psychostimulants such as amphetamine and methylphenidate are indirect agonists that facilitate the action of catecholamines including dopamine (DA), and their effects on motor activity have been hypothesized as being rate dependent. Low baseline rates of activity are increased by stimulants, whereas higher rates are increased to a lesser extent, or even decreased, as a result of drug treatment, such that stimulant-induced change is a negative linear function of the baseline rate of activity (Solanto, 1998, 2002). However, the underlying mechanism remains essentially unknown.

Prepulse inhibition (PPI) is the phenomenon in which a weak prepulse stimulus attenuates the response to a subsequent startling stimulus, providing an operational measure of sensorimo- 
tor gating and a cross-species form of information processing, deficient in patients with schizophrenia and some other neuropsychiatric disorders, including comorbid attention-deficit hyperactivity disorder (ADHD) and Tourette's syndrome (Castellanos et al., 1996; Geyer et al., 2001). Although psychostimulants reduce PPI in normal subjects, they are known to be effective in enhancing attention-related processes (Solanto, 2002) as well as attending PPI (Hawk et al., 2003) in ADHD children. However, stimulant effects on PPI have not been adequately assessed clinically, and with respect to stimulant response of PPI, there is no animal model showing a positive response. To date, understanding of the therapeutic action mechanisms of stimulants is still in its infancy.

In the present study, we demonstrated that Adcyap1 $1^{-1-}$ mice showed psychopathological aspects of hyperactivity and PPI deficits, as well as beneficial responses to amphetamine. Our results give new insights into the mechanisms underlying the therapeutic effects of psychostimulants.

\section{Materials and Methods}

Animals. All animal experiments were performed in accordance with protocols approved by the Animal Care and Use Committee of Graduate School of Pharmaceutical Sciences, Osaka University. Generation of Adcyap $1^{-1-}$ mice by a gene-targeting technique has been reported previously (Hashimoto et al., 2001). The null mutation was backcrossed onto an Institute of Cancer Research mouse background. Wild-type and Adcyap $1^{-1-}$ mice used were obtained from the intercross of heterozygous animals.

PPI analysis. Acoustic startle responses were measured in a startle chamber (SR-LAB; San Diego Instruments, San Diego, CA) using standard methods described previously (Sakaue et al., 2003). The testing session started with a $5 \mathrm{~min}$ acclimatization to the startle chamber in the presence of $65 \mathrm{~dB}$ background white noise. Testing consisted of 40 $120-\mathrm{dB}$ pulses alone and 10 pulses preceded $(100 \mathrm{~ms})$ by a prepulse of 66 , 68,71 , or $77 \mathrm{~dB}$. Pulses were randomly presented with an average of $15 \mathrm{~s}$ between pulses. Twelve no-stimulus trials were included to assess spontaneous activity during testing that was routinely observed to be $10-20$ (arbitrary unit). For drug treatments, animals were placed in the startle chamber just after intraperitoneal injection of amphetamine or $30 \mathrm{~min}$ after intraperitoneal injection of haloperidol. PPI was calculated as a percentage score: PPI $(\%)=(1-[($ startle response for pulse with prepulse) $/($ startle response for pulse alone $)]) \times 100$.

Locomotor activity. Locomotor activity was quantified in plastic activity monitoring boxes $(30 \times 30 \times 30 \mathrm{~cm})$ for $90 \mathrm{~min}$ using an infrared photocell beam detection system Acti-Track (Panlab, Barcelona, Spain) after intraperitoneal injection of drug or saline. The number of jumps was scored for 90 min using video recordings by experienced observers blinded to the mouse genotypes.

Measurement of rectal temperature. Rectal temperature was recorded with a Physitemp Bat 12 digital thermometer (Physitemp Instruments, Clifton, NJ) before and after intraperitoneal drug injection.

Immunohistochemistry. After intraperitoneal injection of amphetamine or saline, mice were placed back into their boxes. Two hours after injection, mice were deeply anesthetized with pentobarbital, perfused transcardially with saline, followed by a solution of $4 \%$ paraformaldehyde in PBS. Frontal sections $(30 \mu \mathrm{m})$ containing medial prefrontal cortices (prelimbic cortex and infralimbic cortex) at $+1.42 \mathrm{~mm}$ from the bregma and dorsomedial striatum at $+0.50 \mathrm{~mm}$ from the bregma (Franklin and Paxinos, 1997) were cut and processed for immunohistochemistry with anti-c-Fos rabbit polyclonal primary antibody (sc-52; Santa Cruz Biotechnology, Santa Cruz, CA) and biotin-labeled antirabbit IgG secondary antibody (Nichirei, Tokyo, Japan). c-Fos-positive nuclei were counted manually by experienced observers blinded to the mouse genotypes.

Statistical analysis. Statistically significant differences were assessed by ANOVA, followed by post hoc Mann-Whitney U test or Tukey's multiple comparison test, where applicable.

\section{Results}

\section{PPI deficits in Adcyap1 $1^{-/-}$mice}

To investigate a possible role of PACAP in sensorimotor gating, PPI was measured in Adcyap1 ${ }^{-1-}$ mice and their wild-type littermate controls. There was no significant difference in startle amplitudes elicited at 100 or $120 \mathrm{~dB}$ between the two groups. Pulse intensities of 65 and $77 \mathrm{~dB}$, selected as background noise and the highest prepulse intensity, respectively, elicited negligible startle when not paired with the startle stimulus in both groups (Fig. $1 \mathrm{~A}$, bottom). Adcyap $1^{-1-}$ mice showed diminished PPI at 71 and $77 \mathrm{~dB}$ prepulse intensities compared with wild-type mice (Fig. 1A, top). To examine the developmental changes of PPI deficits in Adcyap $1^{-1-}$ mice, PPI was tested at postnatal weeks 4, 6 , and 8 . There was no significant difference in startle amplitudes between the two groups at all studied ages (Fig. $1 \mathrm{~B}$, bottom). At postnatal week 4 , PPI levels were similar between the two groups (Fig. $1 B$, top). Although wild-type mice showed an agedependent increase in PPI, there was no significant increase in PPI in Adcyap $1^{-1-}$ mice from 4 to 8 weeks of age. At postnatal weeks 6 and 8, PPI levels were lower in Adcyap $1^{-1-}$ mice when compared with wild-type mice by 44 and $35 \%$, respectively. PPI deficits in Adcyap1 ${ }^{-1-}$ mice were also seen at 14 weeks of age (data not shown).

\section{Effects of psychostimulants on PPI deficits in Adcyap $1^{-/-}$} mice

Dopaminergic systems have been postulated to be involved in the control of PPI (Swerdlow and Geyer, 1998); therefore, the effects of the $\mathrm{D}_{2}$ dopamine receptor blocking antipsychotic haloperidol on PPI deficits were assessed in Adcyap $1^{-1-}$ mice. Haloperidol $\left(0.02\right.$ or $0.2 \mathrm{mg} / \mathrm{kg}$ ) failed to improve PPI deficits in Adcyap $1^{-1-}$ mice (Fig. $1 C$, top) and showed no significant effect on startle amplitudes in both groups (Fig. 1C, bottom). We assessed possible effects of psychostimulants on the PPI deficits in Adcyap1 $1^{-1-}$ mice and found that amphetamine, at a clinically relevant dose range (2 mg/kg) (Gainetdinov and Caron, 2000), reversed PPI deficits to the control level in wild-type mice (Fig. 1 D, top). Consistent with a previous report (Ralph et al., 2001b), a higher dose of amphetamine $(10 \mathrm{mg} / \mathrm{kg})$ tended to reduce PPI in wild-type mice, although there were no significant changes in PPI levels between the two groups. Startle amplitudes were reduced in Adcyap $1^{-1-}$ mice that received $10 \mathrm{mg} / \mathrm{kg}$ amphetamine (Fig. $1 D$, bottom).

\section{Effects of haloperidol and psychostimulants on abnormal jumping behavior in Adcyap $1^{-/-}$mice}

We examined the effects of haloperidol and psychostimulants on explosive jumping behavior in Adcyap $1^{-/-}$mice. Haloperidol effectively reduced the number of jumps in Adcyap $1^{-1-}$ mice (Fig. $2 A$ ). Interestingly, amphetamine and methylphenidate also reduced the number of jumps in Adcyap $1^{-1-}$ mice (Fig. $2 B, C$ ).

\section{Amphetamine-evoked paradoxical antihyperkinetic effect}

Adcyap $1^{-1-}$ mice maintained high initial levels of locomotor activity with reduced thigmotaxis or wall-hugging behavior, an index of anxiety, during the open field test (Hashimoto et al., 2001). As expected, wild-type mice responded to amphetamine $(2 \mathrm{mg} / \mathrm{kg}$ ) with increased locomotor activity (Fig. $3 A$ ); however, in sharp contrast, amphetamine $(2 \mathrm{mg} / \mathrm{kg}$ ) paradoxically attenuated hyperlocomotion in Adcyap $1^{-1-}$ mice (Fig. 3B). Likewise, $10 \mathrm{mg} / \mathrm{kg}$ amphetamine increased locomotor activity in wildtype mice and still produced antihyperkinetic effects in 

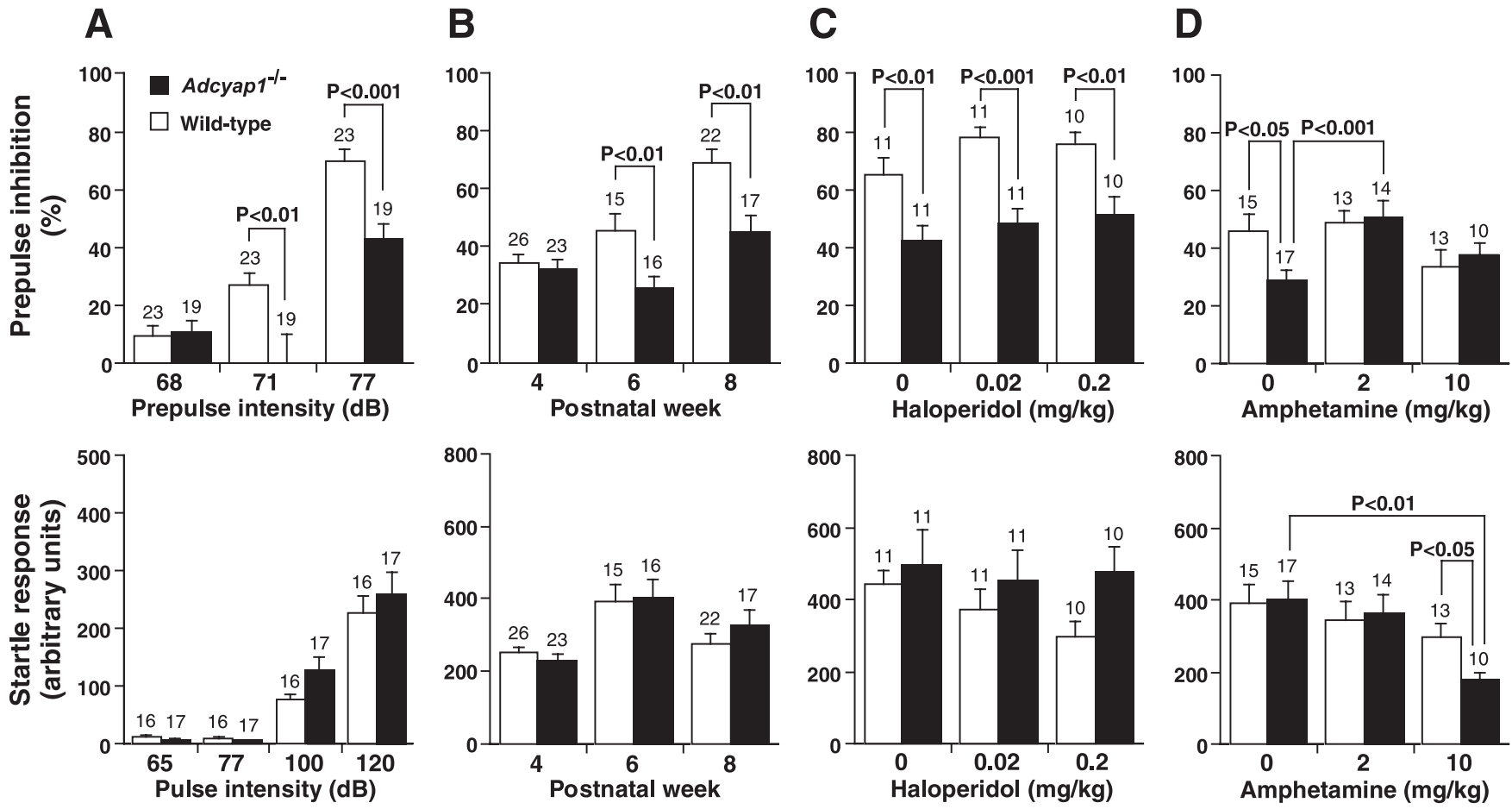

Figure 1. Startle amplitudes without prepulses and PPI of the startle reflex in Adcyap $1^{-1}$ - mice. $\boldsymbol{A}-\boldsymbol{D}$, PPI levels (top) and startle responses (bottom) at different pulse intensities in 8-week-old mice $(\boldsymbol{A})$, at $77 \mathrm{~dB}$ prepulse followed by $120 \mathrm{~dB}$ startle pulses in mice at postnatal weeks 4, 6, and $8(\boldsymbol{B})$, or in 8-week-old mice after pretreatment with haloperidol ( $\boldsymbol{C}$ ) or amphetamine $(\boldsymbol{D})$. The number of wild-type (open bars) and Adcyap $1^{-1-}$ (closed bars) mice are indicated above the bars. Data are expressed as means \pm SEM.
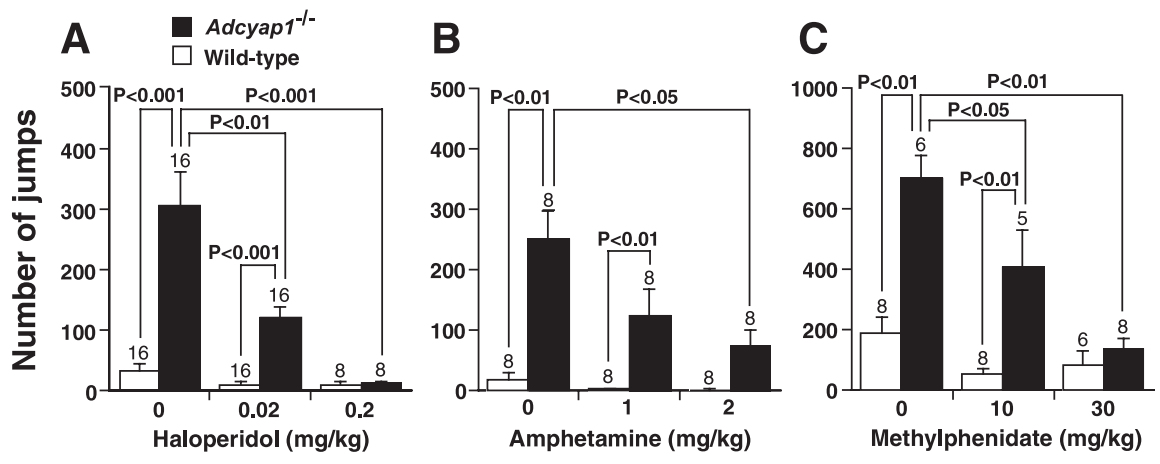

Figure 2. $\quad \boldsymbol{A}-\boldsymbol{C}$, Number of jumps in Adcyap $1^{-1-}$ mice after pretreatment with haloperidol $(\boldsymbol{A})$, amphetamine $(\boldsymbol{B})$, and methylphenidate $(\boldsymbol{C})$. The number of wild-type (open bars) and Adcyap $1^{-1-}$ (closed bars) mice are indicated above the bars. Data are expressed as means \pm SEM.

Adcyap $1^{-1-}$ mice (data not shown). Adcyap1 ${ }^{-1-}$ mice entered the center region more often than wild-type mice. Amphetamine ( $2 \mathrm{mg} / \mathrm{kg}$ ) inhibited such aberrant behavior and, instead, increased thigmotaxis as seen in wild-type mice (Fig. 3C).

\section{Possible involvement of $5-\mathrm{HT}_{1 \mathrm{~A}}$ receptor signaling in the psychobehavioral changes}

We explored possible neurochemical alterations relevant to psychobehavioral changes in Adcyap $1^{-1-}$ mice and found reduced hypothermic response to $5-\mathrm{HT}_{1 \mathrm{~A}}$ agonists. The $5-\mathrm{HT}_{1 \mathrm{~A}}$ agonists 8 -hydroxy-2-(di- $n$-propylamino)tetralin $\quad(8-\mathrm{OH}-$ DPAT) or buspirone significantly decreased rectal temperature in wild-type mice, whereas the response was markedly attenuated in Adcyap $1^{-1-}$ mice (Fig. 4). Therefore, we examined the possible involvement of $5-\mathrm{HT}_{1 \mathrm{~A}}$ signaling in the amphetamine-evoked antihyperkinetic effect in Adcyap $1^{-1-}$ mice. The selective $5-\mathrm{HT}_{1 \mathrm{~A}}$ receptor antagonist $N$-[2-[4-(2-methoxyphenyl)1-piperazinyl] ethyl]-N-(2-pyridinyl)cyclohexanecarboxamide (WAY-100635) (0.3 $\mathrm{mg} / \mathrm{kg}$ ) blocked the action of amphetamine (Fig. 5B). We also found that amphetamine produced paradoxical calming effects in wild-type mice that received $8-\mathrm{OH}-\mathrm{DPAT}$ $(0.05 \mathrm{mg} / \mathrm{kg}) \quad$ (Fig. 5A). Neither WAY-100635 nor 8-OH-DPAT alone influenced locomotor activity in wild-type and Adcyap1 ${ }^{-1-}$ mice (Fig. 5C,D).

c-Fos-positive neurons were increased in prefrontal cortex in amphetaminetreated Adcyap $1^{-/-}$mice

Presynaptic 5- $\mathrm{HT}_{1 \mathrm{~A}}$ autoreceptors have been shown to mediate the hypothermic response, and receptor density correlates with the hypothermic response to $5-\mathrm{HT}_{1 \mathrm{~A}}$ agonists (Aguirre et al., 1998). Therefore, we performed reverse transcription-PCR analysis to quantify $5-\mathrm{HT}_{1 \mathrm{~A}}$ and other $5-\mathrm{HT}$ receptor mRNA levels, as well as microarray analysis. However, to date, we have not confirmed changes in expression of mRNA for 5-HT receptors and other genes that are probably responsible for altered psychomotor functions in Adcyap ${ }^{-1-}$ mice (data not shown).

There is evidence implicating the prefrontal cortex in the pathophysiology of motor dysregulation as well as PPI deficits (Swerdlow and Geyer, 1998; Goldman-Rakic et al., 2000). Therefore, we examined c-Fos expression as a marker for postsynaptic activity to define the pattern of neurons excited by amphetamine (Fig. 6). The number of c-Fos-positive neurons increased in the medial prefrontal cortex in amphetamine-treated Adcyap $1^{-1-}$ 
mice compared with wild-type mice, suggesting hyperactivation of Adcyap $1^{-1-}$ prefrontal cortical neurons by amphetamine. Amphetamine-induced increase in the number of c-Fos-positive neurons in the dorsomedial striatum (Fig. 6) and other regions, including the cingulate cortex and nucleus accumbens (data not shown), was not significantly different between the two groups.

\section{Discussion}

Psychostimulants are controlled substances, because they have long-term sensitizing effects and a potential for abuse, and they may also be neurotoxic. However, psychostimulant treatment has long been recognized to attenuate hyperactivity, paradoxically, and often to improve cognitive performance (Castellanos and Tannock, 2002; Solanto, 2002; Garland and Kirkpatrick, 2004). Animal studies have demonstrated that psychostimulants have biphasic effects on motor activity and cognitive processes (Solanto, 1998), but underlying mechanisms remain mostly uncharacterized. We demonstrated that Adcyap $1^{-1-}$ mice showed psychopathological changes, including PPI deficits, and investigated the effects of psychostimulants on hyperactivity, PPI deficits, and excessive jumping activity, as well as the role of 5- $\mathrm{HT}_{1 \mathrm{~A}}$ signaling in the paradoxical actions of amphetamine on hyperactivity. These findings seem a long way from the clinical disorders of hyperkinesia and cognitive impairment, but we hope to provide models with some typical features of psychostimulant responses in these disorders.

There is considerable evidence for the involvement of dopaminergic systems in the control of PPI (Geyer et al., 2001). We demonstrated that, although hyperlocomotion (Hashimoto et al., 2001) and jumping behavior in Adcyap $1^{-1-}$ mice were effectively attenuated by haloperidol (a $\mathrm{D}_{2}$ antagonist), PPI deficits were not reversed by haloperidol. Other than DA, glutamatergic systems are important for modulating PPI (Geyer et al., 2001). PPI is reduced in rodents and humans by noncompetitive NMDA antagonists, such as phencyclidine and dizocilpine $[(+)$-5-methyl-10,11-dihydro-5 $H$-dibenzo [a,d] cyclohepten-5,10-imine maleate]. Several studies have shown that PACAP can potentiate NMDA receptor functions (Stella and Magistretti, 1996; Liu and Madsen, 1997; Pellegri et al., 1998). Recently, we showed that Adcyap $1^{-1-}$ mice do not exhibit inflammatory or neuropathic pain, and PACAP is required for functional coupling of neuronal nitric oxide synthase to NMDA receptors in the spinal cord for chronic pain to occur (Mabuchi et al., 2004). This raises the possibility that similar mechanisms might be involved in psychomotor

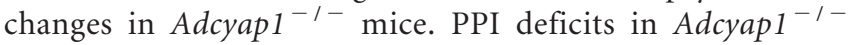
mice may therefore be ascribable in part to NMDA hypofunction.

One of the most striking findings in our study was that amphetamine completely reversed PPI deficits in Adcyap $1^{-1-}$ mice and, to our knowledge, this is the first animal model showing PPI deficits and paradoxical responses to psychostimulants. DA transporter knock-out mice were shown to exhibit PPI deficits, which were improved by the $\mathrm{D}_{2}$ receptor antagonist raclopride (Ralph et al., 2001a) and the 5- $\mathrm{HT}_{2 \mathrm{~A}}$ receptor antagonist M100907 (Barr et al., 2004). Therefore, it will be interesting to investigate the effects of psychostimulants on PPI deficits in DA transporter knock-out mice.

Adcyap $1^{-1-}$ mice did not show a significant increase in PPI from 4 to 8 weeks of age, suggesting that the process of sensorimotor gating remains functionally immature. Developmental issues are considered to be particularly relevant to understanding PPI deficits in humans, because PPI appears to develop in children 5-8 years of age (Ornitz et al., 1990). In addition, Adcyap $1^{-1-}$ mice showed a slight decrease in 5-HT metabolite 5-hydroxyindoleacetic acid in their brain (Hashimoto et al., 2001), and this was manifested at 4 weeks of age (the earliest age tested) (our unpublished data). Several lines of evidence suggest that PACAP acts as a neurotrophic factor and plays diverse roles in mammalian neurogenesis (Arimura, 1998; Vaudry et al., 2000). Therefore, it is conceivable that developmental defects in 5-HT systems, or the relative balance of tone between 5-HT and other neurotransmitter systems, such as the glutamatergic system, may contribute to PPI deficits and hyperactivity in Adcyap $1^{-1-}$ mice. However, this does not exclude the possibility that PACAP is actively involved in psychological functions. Three 


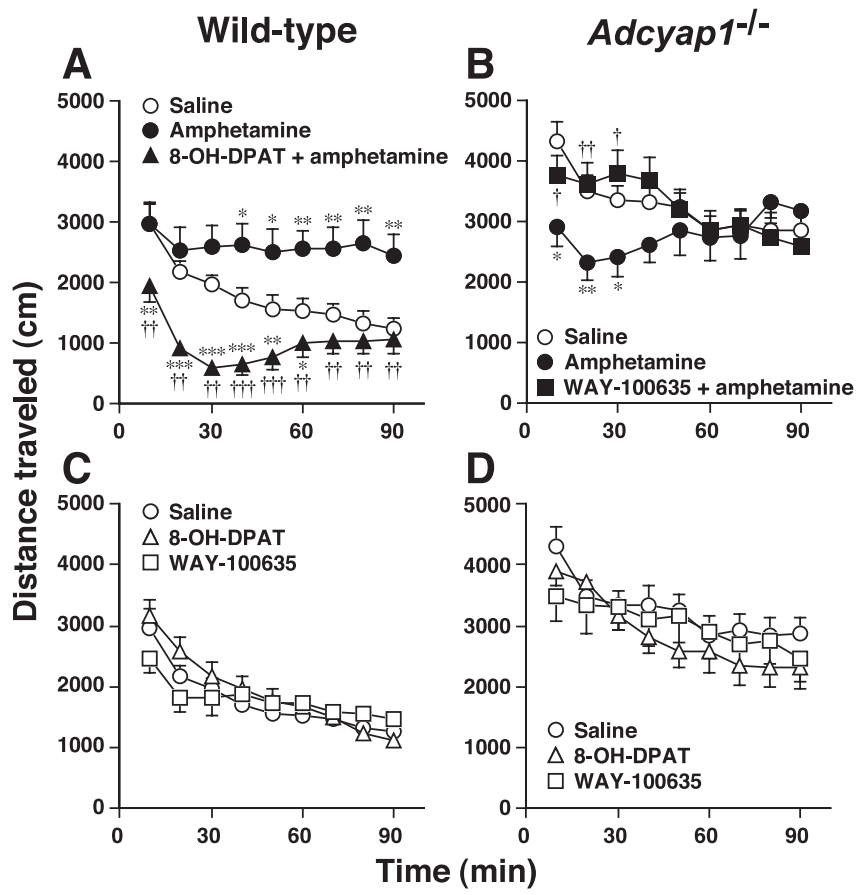

Figure 5. Locomotor activity in the open field test. $\boldsymbol{A}-\boldsymbol{D}$, Locomotor activity in wild-type ( $\boldsymbol{A}$, C) and Adcyap ${ }^{-1-}(\boldsymbol{B}, \boldsymbol{D})$ mice that received $0.05 \mathrm{mg} / \mathrm{kg} 8-0 \mathrm{H}-\mathrm{DPAT}$ (triangles), $0.3 \mathrm{mg} / \mathrm{kg}$ WAY-100635 (squares), or saline (circles) either alone (open symbols) or in combination with 2 $\mathrm{mg} / \mathrm{kg}$ amphetamine (closed symbols). The results of the experiment with amphetamine or saline alone are the same as those in Figure $3 . n=15-16$ per group. ${ }^{*} p<0.05,{ }^{* *} p<0.01$, and ${ }^{* * *} p<0.001$ versus saline alone; ${ }^{\dagger} p<0.05,{ }^{t \dagger} p<0.01$, and ${ }^{t+t} p<0.001$ versus amphetamine. Data are expressed as means \pm SEM.

different PACAP knock-out lines (Gray et al., 2001; Hamelink et al., 2002; Colwell et al., 2004) developed separately from our colony have been reported to also show dysfunction of lipid and carbohydrate metabolism, cold hypersensitivity, impaired catecholamine regulation in the sympathoadrenal axis, and deficits in the circadian light response, suggesting putative developmental and/or neuroplastic abnormalities in these mutant mice.

It has been postulated that prefrontal cortex dysregulation may lead to disinhibition in targets of the prefrontal cortex projection, with a possible relevance to dysregulation of motor functions and PPI (Swerdlow and Geyer, 1998; Goldman-Rakic et al., 2000). In vivo microdialysis showed that basal and amphetamineinduced release of extracellular DA and 5-HT in the prefrontal cortex did not differ significantly between Adcyap $1^{-1-}$ and wildtype mice $\left(\mathrm{DA}, F_{(20,180)}=0.198\right.$; not significant; $5-\mathrm{HT}, F_{(20,180)}=$ 1.069; not significant). However, the number of c-Fos-positive neurons increased in the medial prefrontal cortex of Adcyap $1^{-1-}$ mice compared with wild-type mice after amphetamine administration. This result raises the possibility that hyperactivation of prefrontal cortical neurons by amphetamine might result in an increased inhibitory control by prefrontal neurons in Adcyap $1^{-1-}$ mice. It has been demonstrated that c-fos mRNA expression in the frontal cortex is increased by environmental novelty, but this effect is not further increased by amphetamine (Badiani et al., 1998). Likewise, when exposed to novelty (alone), the increase in c-Fos-positive neurons in the prefrontal cortex tended to be greater in Adcyap1 $1^{-1-}$ mice compared with wildtype mice, but the effect of novelty was similar to that of amphetamine in the respective groups of mice (data not shown). Additional studies to define and characterize these cell populations responsible for the effects of amphetamine and novelty will help
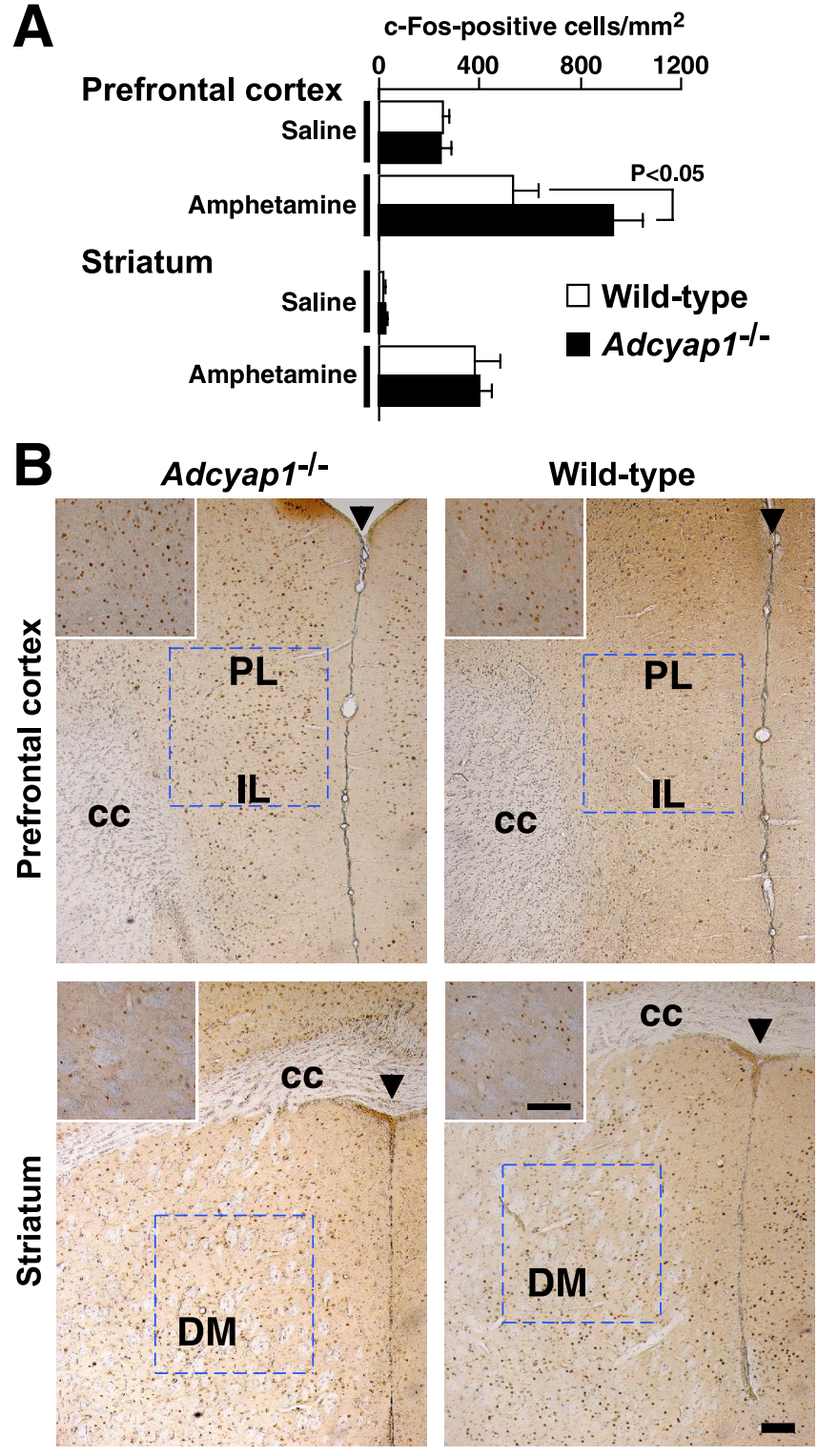

Figure 6. c-Fos-positive neurons in medial prefrontal cortex and dorsomedial striatum in amphetamine-treated Adcyap $1^{-1-}$ mice. $\boldsymbol{A}$, Number of c-Fos-positive neurons in the outlined regions in $\boldsymbol{B}$ in wild-type (open bars) and $A d c y a p 1^{-1-}$ (closed bars) mice that received $10 \mathrm{mg} / \mathrm{ml}$ amphetamine. $n=6-7$ per group. $\boldsymbol{B}$, Photomicrographs showing representative c-Fos labeling in medial prefrontal cortex (top panels) and dorsomedial striatum (bottom panels) in amphetamine-treated Adcyap $1^{-1-}$ (left panels) and wild-type (right panels) mice. Insets, High magnifications of c-Fos staining. PL, Prelimbic cortex; IL, infralimbic cortex; DM, dorsomedial striatum; cc, corpus callosum; arrowheads, midline. Scale bars, $100 \mu \mathrm{m}$. Data are expressed as means \pm SEM.

to investigate the neuronal mechanisms for psychostimulant treatment.

Studies in DA transporter knock-out mice suggest the tantalizing possibility that hyperkinetic behavior might be controlled through precise targeting of 5-HT receptors, or even through enhanced availability of 5-HT precursors (Gainetdinov et al., 1999). The latter possibility is still controversial, because therapeutic efficacy of selective serotonergic drugs is not commonly recognized in treating hyperkinetic disorder (Gainetdinov and Caron, 2000; Popper, 2000; Davids et al., 2003). The reason for this may be simply a result of the large multiplicity of 5-HT receptor subtypes and existence of multiple 5-HT autoreceptors, having sometimes opposing or no effects on locomotion (Geyer, 
1996; Lucki, 1998). Regarding the former possibility (precise targeting of 5-HT receptors), the present study showed that WAY100635 blocked the amphetamine-elicited antihyperkinetic effect in Adcyap $1^{-1-}$ mice, and that amphetamine produced a paradoxical calming effect in 8-OH-DPAT-treated wild-type mice. Previous reports show that 8-OH-DPAT attenuates psychostimulant-induced behavioral sensitization and increment in locomotor activity, where both presynaptic and postsynaptic $5-\mathrm{HT}_{1 \mathrm{~A}}$ receptor-dependent mechanisms are suggested to be involved (Przegalinski and Filip, 1997; Przegalinski et al., 2000; Carey et al., 2005). However, the paradoxical calming effect of psychostimulant plus $5-\mathrm{HT}_{1 \mathrm{~A}}$ receptor agonist combination has hitherto not been addressed and may provide provocative clues into the mechanisms of the therapeutic effects of psychostimulants. Together with previous reports, the present data suggest that the targeting of $5-\mathrm{HT}_{1 \mathrm{~A}}$ receptors, adjunctive to psychostimulants, are promising for pharmaceutical intervention in hyperkinetic disorder.

Histochemical studies have shown that PACAP immunoreactivity is present in several brain regions involved in the DA and 5-HT systems, including the cerebral cortex, nucleus accumbens, amygdala, hypothalamus, substantia nigra, ventral tegmental area, and dorsal raphe nucleus (Masuo et al., 1993; Piggins et al., 1996). PAC $_{1}$ receptors are expressed broadly in both the target areas and nuclei of origin of these monoaminergic systems (Hashimoto et al., 1996). VPAC 1 and $\mathrm{VPAC}_{2}$ receptors are also expressed in these systems (Usdin et al., 1994). These observations suggest a functional relationship between PACAP and monoaminergic neurons. Serotonergic cell bodies are located mainly in the raphe nuclei, whereas 5-HT-containing terminals are widely distributed in the brain. Among 5-HT receptor subtypes, $5-\mathrm{HT}_{1 \mathrm{~A}}$ receptors are expressed presynaptically as the primary somatodendritic autoreceptor on serotonergic raphe neurons and postsynaptically in a variety of other neurons (Barnes and Sharp, 1999). Although there is no report of colocalization analysis between PACAP/PACAP receptors and 5-HTcontaining elements, it is plausible that PACAP modulates the serotonergic system both at the origin and innervation sites. The reduced hypothermic response to $5-\mathrm{HT}_{1 \mathrm{~A}}$ agonists in Adcyap $1^{-1-}$ mice supports the functional coupling between the two systems.

The supplemental figure (available at www.jneurosci.org as supplemental material) shows a schematic representation of possible relationships between locomotor activity and degree of stimulation of $5-\mathrm{HT}_{1 \mathrm{~A}}$ systems in amphetamine-treated Adcyap $1^{-1-}$ and wild-type mice. Neither WAY-100635 nor 8-OH-DPAT alone influenced locomotor activity in both groups, indicating that changes in $5-\mathrm{HT}_{1 \mathrm{~A}}$ systems per se do not influence locomotor activity. The observations that WAY-100635 blocked the amphetamine-elicited antihyperkinetic effect in Adcyap $1^{-1-}$ mice, and that amphetamine induced hypokinesia in $8-\mathrm{OH}$ DPAT-treated wild-type mice, indicate that the $5-\mathrm{HT}_{1 \mathrm{~A}}$ relative activity has a great influence on the effects of amphetamine. Psychostimulants have been hypothesized to exert rate-dependent effects that show a negative linear correlation with the baseline rate of activity (Solanto, 1998, 2002). The present results suggest that the stimulation level of $5-\mathrm{HT}_{1 \mathrm{~A}}$ systems, or the relative balance with other 5-HT receptor subtypes or neurotransmitter systems, might be involved in the rate-dependent effects elicited by psychostimulants.

Many psychiatric disorders are multifactorial, reflecting longitudinal and complex interactions of causative agents, including genetic and environmental factors. Pathogenesis remains poorly understood; therefore, animal models provide useful tools to investigate the mechanisms underlying human diseases and for the design of new treatments (Lipska and Weinberger, 2000). Although, Adcyap1 ${ }^{-1-}$ mice do not provide an animal model of some specific psychiatric disorder per se, the present study may provide insights into the pathophysiology and etiology of hyperkinetic disorder and other disorders including disrupted PPI.

\section{References}

Aguirre N, Ballaz S, Lasheras B, Del-Rio J (1998) MDMA ("Ecstasy”) enhances $5-\mathrm{HT}_{1 \mathrm{~A}}$ receptor density and 8 -OH-DPAT-induced hypothermia: blockade by drugs preventing 5-hydroxytryptamine depletion. Eur J Pharmacol 346:181-188.

Arimura A (1998) Perspectives on pituitary adenylate cyclase activating polypeptide (PACAP) in the neuroendocrine, endocrine, and nervous systems. J Physiol (Japan) 48:301-331.

Badiani A, Oates MM, Day HE, Watson SJ, Akil H, Robinson TE (1998) Amphetamine-induced behavior, dopamine release, and c-fos mRNA expression: modulation by environmental novelty. J Neurosci 18:10579-10593.

Barnes NM, Sharp T (1999) A review of central 5-HT receptors and their function. Neuropharmacology 38:1083-1152.

Barr AM, Lehmann-Masten V, Paulus M, Gainetdinov RR, Caron MG, Geyer MA (2004) The selective serotonin-2A receptor antagonist M100907 reverses behavioral deficits in dopamine transporter knockout mice. Neuropsychopharmacology 29:221-228.

Carey RJ, DePalma G, Damianopoulos E, Shanahan A, Muller CP, Huston JP (2005) Evidence that the 5- $\mathrm{HT}_{1 \mathrm{~A}}$ autoreceptor is an important pharmacological target for the modulation of cocaine behavioral stimulant effects. Brain Res 1034:162-171.

Castellanos FX, Tannock R (2002) Neuroscience of attention-deficit/hyperactivity disorder: the search for endophenotypes. Nat Rev Neurosci 3:617-628.

Castellanos FX, Fine EJ, Kaysen D, Marsh WL, Rapoport JL, Hallett M (1996) Sensorimotor gating in boys with Tourette's syndrome and ADHD: preliminary results. Biol Psychiatry 39:33-41.

Colwell CS, Michel S, Itri J, Rodriguez W, Tam J, Lelievre V, Hu Z, Waschek JA (2004) Selective deficits in the circadian light response in mice lacking PACAP. Am J Physiol Regul Integr Comp Physiol 287:R1194-R1201.

Davids E, Zhang K, Tarazi FI, Baldessarini RJ (2003) Animal models of attention-deficit hyperactivity disorder. Brain Res Brain Res Rev 42:1-21.

Franklin KBJ, Paxinos G (1997) The mouse brain in stereotaxic coordinates. San Diego: Academic.

Gainetdinov RR, Caron MG (2000) An animal model of attention deficit hyperactivity disorder. Mol Med Today 6:43-44.

Gainetdinov RR, Wetsel WC, Jones SR, Levin ED, Jaber M, Caron MG (1999) Role of serotonin in the paradoxical calming effect of psychostimulants on hyperactivity. Science 283:397-401.

Garland M, Kirkpatrick P (2004) Atomoxetine hydrochloride. Nat Rev Drug Discov 3:385-386.

Geyer MA (1996) Serotonergic functions in arousal and motor activity. Behav Brain Res 73:31-35.

Geyer MA, Krebs-Thomson K, Braff DL, Swerdlow NR (2001) Pharmacological studies of prepulse inhibition models of sensorimotor gating deficits in schizophrenia: a decade in review. Psychopharmacology 156:117-154.

Goldman-Rakic PS, Muly III EC, Williams GV (2000) $D_{1}$ receptors in prefrontal cells and circuits. Brain Res Brain Res Rev 31:295-301.

Gray SL, Cummings KJ, Jirik FR, Sherwood NM (2001) Targeted disruption of the pituitary adenylate cyclase-activating polypeptide gene results in early postnatal death associated with dysfunction of lipid and carbohydrate metabolism. Mol Endocrinol 15:1739-1747.

Hamelink C, Tjurmina O, Damadzic R, Young WS, Weihe E, Lee HW, Eiden LE (2002) Pituitary adenylate cyclase-activating polypeptide is a sympathoadrenal neurotransmitter involved in catecholamine regulation and glucohomeostasis. Proc Natl Acad Sci USA 99:461-466.

Hashimoto H, Nogi H, Mori K, Ohishi H, Shigemoto R, Yamamoto K, Matsuda T, Mizuno N, Nagata S, Baba A (1996) Distribution of the mRNA for a pituitary adenylate cyclase-activating polypeptide receptor in the rat brain: an in situ hybridization study. J Comp Neurol 371:567-577.

Hashimoto H, Shintani N, Tanaka K, Mori W, Hirose M, Matsuda T, Sakaue 
M, Miyazaki J, Niwa H, Tashiro F, Yamamoto K, Koga K, Tomimoto S, Kunugi A, Suetake S, Baba A (2001) Altered psychomotor behaviors in mice lacking pituitary adenylate cyclase-activating polypeptide (PACAP). Proc Natl Acad Sci USA 98:13355-13360.

Hashimoto H, Shintani N, Baba A (2006) New insights into the central PACAPergic system from the phenotypes in PACAP- and PACAP receptor-knockout mice. Ann NY Acad Sci, in press.

Hawk Jr LW, Yartz AR, Pelham Jr WE, Lock TM (2003) The effects of methylphenidate on prepulse inhibition during attended and ignored prestimuli among boys with attention-deficit hyperactivity disorder. Psychopharmacology 165:118-127.

Kawaguchi C, Tanaka K, Isojima Y, Shintani N, Hashimoto H, Baba A, Nagai $\mathrm{K}$ (2003) Changes in light-induced phase shift of circadian rhythm in mice lacking PACAP. Biochem Biophys Res Commun 310:169-175.

Lipska BK, Weinberger DR (2000) To model a psychiatric disorder in animals: schizophrenia as a reality test. Neuropsychopharmacology 23:223-239.

Liu GJ, Madsen BW (1997) PACAP38 modulates activity of NMDA receptors in cultured chick cortical neurons. J Neurophysiol 78:2231-2234.

Lucki I (1998) The spectrum of behaviors influenced by serotonin. Biol Psychiatry 44:151-162.

Mabuchi T, Shintani N, Matsumura S, Okuda-Ashitaka E, Hashimoto H, Muratani T, Minami T, Baba A, Ito S (2004) Pituitary adenylate cyclaseactivating polypeptide is required for the development of spinal sensitization and induction of neuropathic pain. J Neurosci 24:7283-7291.

Masuo Y, Suzuki N, Matsumoto H, Tokito F, Matsumoto Y, Tsuda M, Fujino M (1993) Regional distribution of pituitary adenylate cyclase activating polypeptide (PACAP) in the rat central nervous system as determined by sandwich-enzyme immunoassay. Brain Res 602:57-63.

Ornitz EM, Guthrie D, Lane SJ, Sugiyama T (1990) Maturation of startle facilitation by sustained prestimulation. Psychophysiology 27:298-308.

Pellegri G, Magistretti PJ, Martin JL (1998) VIP and PACAP potentiate the action of glutamate on BDNF expression in mouse cortical neurones. Eur J Neurosci 10:272-280.

Piggins HD, Stamp JA, Burns J, Rusak B, Semba K (1996) Distribution of pituitary adenylate cyclase activating polypeptide (PACAP) immunoreactivity in the hypothalamus and extended amygdala of the rat. J Comp Neurol 376:278-294.

Popper CW (2000) Pharmacologic alternatives to psychostimulants for the treatment of attention-deficit/hyperactivity disorder. Child Adolesc Psychiatr Clin N Am 9:605-646.
Przegalinski E, Filip M (1997) Stimulation of serotonin (5-HT) ${ }_{1 \mathrm{~A}}$ receptors attenuates the locomotor, but not the discriminative, effects of amphetamine and cocaine in rats. Behav Pharmacol 8:699-706.

Przegalinski E, Siwanowicz J, Baran L, Filip M (2000) Activation of seroto$\operatorname{nin}(5-\mathrm{HT})_{1 \mathrm{~A}}$ receptors inhibits amphetamine sensitization in mice. Life Sci 66:1011-1019.

Ralph RJ, Paulus MP, Fumagalli F, Caron MG, Geyer MA (2001a) Prepulse inhibition deficits and perseverative motor patterns in dopamine transporter knock-out mice: differential effects of $\mathrm{D}_{1}$ and $\mathrm{D}_{2}$ receptor antagonists. J Neurosci 21:305-313.

Ralph RJ, Paulus MP, Geyer MA (2001b) Strain-specific effects of amphetamine on prepulse inhibition and patterns of locomotor behavior in mice. J Pharmacol Exp Ther 298:148-155.

Sakaue M, Ago Y, Baba A, Matsuda T (2003) The $5-\mathrm{HT}_{1 \mathrm{~A}}$ receptor agonist MKC-242 reverses isolation rearing-induced deficits of prepulse inhibition in mice. Psychopharmacology 170:73-79.

Shintani N, Mori W, Hashimoto H, Imai M, Tanaka K, Tomimoto S, Hirose M, Kawaguchi C, Baba A (2002) Defects in reproductive functions in PACAP-deficient female mice. Regul Pept 109:45-48.

Solanto MV (1998) Neuropsychopharmacological mechanisms of stimulant drug action in attention-deficit hyperactivity disorder: a review and integration. Behav Brain Res 94:127-152.

Solanto MV (2002) Dopamine dysfunction in AD/HD: integrating clinical and basic neuroscience research. Behav Brain Res 130:65-71.

Stella N, Magistretti PJ (1996) Vasoactive intestinal peptide (VIP) and pituitary adenylate cyclase-activating polypeptide (PACAP) potentiate the glutamate-evoked release of arachidonic acid from mouse cortical neurons. Evidence for a cAMP-independent mechanism. J Biol Chem 271:23705-23710.

Swerdlow NR, Geyer MA (1998) Using an animal model of deficient sensorimotor gating to study the pathophysiology and new treatments of schizophrenia. Schizophr Bull 24:285-301.

Tanaka K, Hashimoto H, Shintani N, Yamamoto A, Baba A (2004) Reduced hypothermic and hypnotic responses to ethanol in PACAP-deficient mice. Regul Pept 123:95-98.

Usdin TB, Bonner TI, Mezey E (1994) Two receptors for vasoactive intestinal polypeptide with similar specificity and complementary distributions. Endocrinology 135:2662-2680.

Vaudry D, Gonzalez BJ, Basille M, Yon L, Fournier A, Vaudry H (2000) Pituitary adenylate cyclase-activating polypeptide and its receptors: from structure to functions. Pharmacol Rev 52:269-324. 